\title{
Growth Mechanism of ZnO Films Deposited by Spray Pyrolysis Technique
}

\author{
Bhavana Godbole $^{1}$, Nitu Badera ${ }^{2}$, Shyambihari Shrivastava², Deepti Jain ${ }^{3}$, Vganesan Ganesan ${ }^{3}$ \\ ${ }^{1}$ Department of Applied Physics, Jabalpur Engineering College, Jabalpur, India; ${ }^{2}$ School of Studies in Physics, Vikram University, \\ Ujjain, India; ${ }^{3}$ UGC-DAE, Consortium of Scientific Researches, Indore, India. \\ Email: bhavanassp@gmail.com
}

Received November $26^{\text {th }}, 2010$; revised January $17^{\text {th }}, 2011$; accepted May $17^{\text {th }}, 2011$.

\begin{abstract}
Transparent Zinc Oxide $(\mathrm{ZnO})$ thin films having different thickness are prepared by using Spray pyrolysis technique. Structural and morphological behavior has been studied by using atomic force microscopy and $x$-ray diffraction. The scaling behavior obtained by using height-height correlation method shows that, films with different thickness are developed under non-equilibrium condition behaves as self-affine surfaces. With the increase in thickness, the grain size as well as activation energy have found to be decreased.
\end{abstract}

Keywords: Nano-Crystalline Materials, Thin Film, Atomic Force Microscope, Structure and Morphology, Thickness

\section{Introduction}

$\mathrm{ZnO}$ is a fascinating material for different applications in both microelectronic and optoelectronic devices. It is a wide-band gap oxide semiconductor with a direct energy gap of about $3.37 \mathrm{eV}$. It has found numerous applications, such as surface acoustic wave devices [1], piezoelectric devices [2], ultra sonic transducers [3], ultraviolet photo detectors [4], gas sensors [5] etc. The properties of thin films, which are the basis of their application in technological devices, depend on their surface properties, particularly on the surface roughness. Due to the interest related to the specific properties of transparent metal oxide thin films, recent studies are focused in the correlation of surface with deposition parameters and physical properties. Many deposition techniques have been applied for the production of $\mathrm{ZnO}$ films in order to improve their properties [6-15]. Thus, the knowledge of the mechanisms that determine the film structure has motivated a large amount of research during the last years. The physical properties of the thin films depend not only on the morphology of the sample but also on the preparation route, thickness of the sample and grain sizes. Reproducible properties are achieved only when the thickness and deposition parameters are kept constant. In case of optical devices especially as interference filters, antireflection coatings etc, the success of fabrication depend on the deposition of specific thickness [16]. In the present work, we have reported the dependence of thickness on surface topography and growth mechanism involved during the deposition.

\section{Sample Preparation}

The deposition of $\mathrm{ZnO}$ films is carried out by using simple, economic and home made Spray pyrolysis (SP) technique. The starting solution consists of $0.2 \mathrm{M}$ of zinc nitrate dissolved in distilled water. The films have been deposited on ultrasonically cleaned glass substrates kept at $400^{\circ} \mathrm{C}$. The atomization of the solution in the fine droplets was affected by spray nozzle with the help of compressed air, during the course of the spray. The spray rate of $1 \mathrm{~mL} \cdot \mathrm{min}^{-1}$ was maintained and the distance between tip of nozzle and the substrate was kept at $28 \mathrm{~cm}$. In order to obtain different thickness of films different volumes of precursor solution say $25 \mathrm{~mL}, 50 \mathrm{~mL}, 75 \mathrm{~mL}$, and $100 \mathrm{~mL}$ was sprayed on preheated glass substrates respectively and their thickness is calculated by weight difference method. The aqueous solution of zinc nitrate gets thermally decomposes when fallowing over the surface of preheated substrates. This results in the formation of well adherent and uniform $\mathrm{ZnO}$ film. The as deposited films of $\mathrm{ZnO}$ are transparent with faint white tint. The chemical reaction involved is as fallows:

$$
\begin{aligned}
& 2 \mathrm{Zn}\left(\mathrm{NO}_{3}\right)_{2} \cdot 6 \mathrm{H}_{2} \mathrm{O}+\mathrm{O}_{2} \\
& \rightarrow 2 \mathrm{ZnO}_{\downarrow}+4 \mathrm{NO}_{2}^{\uparrow}+2 \mathrm{O}_{2}^{\uparrow}+12 \mathrm{H}_{2} \mathrm{O}
\end{aligned}
$$

The structural studies of the prepared $\mathrm{ZnO}$ thin films 
are done by means of X-ray diffractometer (Rigaku RINT 2000) with $\mathrm{CuK} \alpha$ radiation having the wavelength of $1.5418^{\circ} \mathrm{A}$ and in the range of $2 \theta=5^{\circ}-80^{\circ}$. Continuous scanning was done with the slow scanning speed with small time constant. The surface morphology (grain size and surface roughness) was measured by using Nanoscope-E atomic force microscope (AFM). These measurements are carried out by using a silicon nitride tip with contact mode at room temperature. The electrical measurements are carried out by using home made dc-two probe resistivity set up.

\section{Results and Discussion}

In the present work, we have deposited $25 \mathrm{~mL}, 50 \mathrm{~mL}$, $75 \mathrm{~mL}$ and $100 \mathrm{~mL}$ of precursor solution on to the preheated glass substrate. The thicknesses of the films were calculated by using weight difference method were found to be increase with the amount of precursor solution used for spray. The thickness so obtained is shown in Table 1. The XRD spectra corresponding to the film deposited for $25 \mathrm{~mL}$ of precursor solution is shown in Figure 1. It is found that, the films are polycrystalline with hexagonal wurtzite structure [17]. In pure $\mathrm{ZnO}$ the most intensive peak has a strong c-axis orientation along (002) direction and found to be at $2 \theta=34.48^{\circ}$. No extra peak was observed in the XRD pattern. The lattice constant a and $\mathrm{c}$ was found to be $3.2499 \mathrm{~nm}$ and $5.20 \mathrm{~nm}$ respectively.

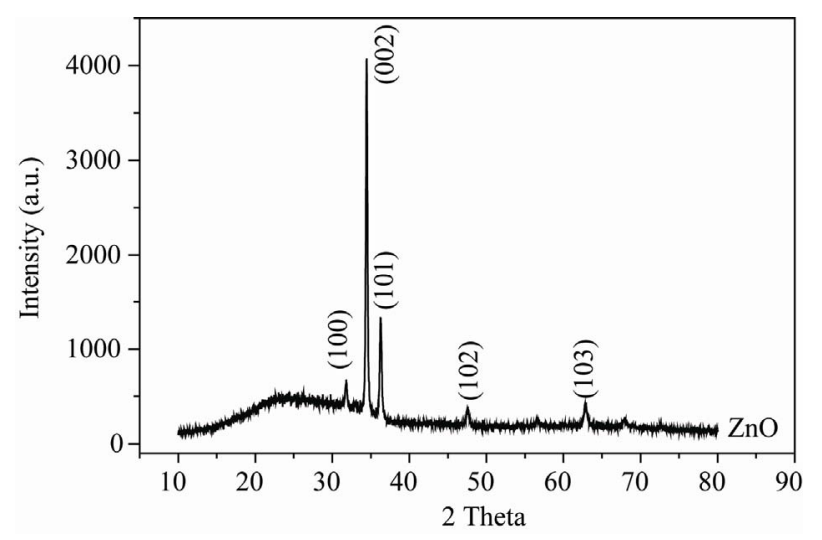

Figure 1. XRD spectra for $\mathrm{ZnO}$ thin film.

Table 1. The variation in thickness, grain size and activation energy with amount of spray solution.

\begin{tabular}{cccc}
\hline $\begin{array}{c}\text { Spray Solution } \\
(\mathbf{m L})\end{array}$ & $\begin{array}{c}\text { Thickness } \\
(\mathbf{n m})\end{array}$ & $\begin{array}{c}\text { Grain size } \\
\mathbf{( n m})\end{array}$ & $\begin{array}{c}\text { Activation band } \\
\text { gap Ea (eV) }\end{array}$ \\
\hline 25 & 98 & 167.9 & 0.55 \\
50 & 193 & $127.5,160.9$ & 0.57 \\
75 & 284 & $150.8,182.5$ & 0.34 \\
100 & 386 & 143.0 & 0.26 \\
\hline
\end{tabular}

The AFM measurements could provide information regarding the surface morphology of films and this capability might be used to investigate the nature of the deposited thin film like the roughness and size of the grains. A careful analysis of roughness can yield information regarding the kind of growth that is taken place while film is formed.

In order to realize the grain size distribution and roughness as a function of film thickness, the AFM data has been analyzed as follows: AFM images along with its lateral force images for the case of $\mathrm{ZnO}$ films with different volumetric concentration have been displayed in Figure 2(a-d).

The grain sizes were measured for all the films and their statistical distributions are plotted in Figure 3(a-d). It is observed that the grain size decreases with the increase in thickness.

The growth mechanism could be understood by using concept of scaling. It was first introduced by Family et al. [18] to provide a frame work for fractal like topologies.

The solid films grown under far from equilibrium conditions are predicted to have self-affine surfaces. The fundamental assumption is that all rough surfaces exhibit perpendicular fluctuations, which are characterized by their root mean square (rms) width.

$$
\sigma=\left\langle Z(x, y)^{2}\right\rangle^{1 / 2}
$$

where

$$
Z(x, y)=h(x, y)-\langle h(x, y)\rangle
$$

and $h(x, y)$ are height fluctuations, $\langle h(x, y)\rangle$ is spatial average over a planner reference structure. The films grown under non-equilibrium conditions are also expected to develop the self-affine surfaces [19] whose rms widths scale with the time $t$ and length $L$ as fallows;

$$
\sigma(L, t)=L^{\alpha} f\left(t / L^{\alpha / \beta}\right)
$$

where,

$$
\begin{gathered}
\sigma(L) \sim L^{\alpha} \text { for } t / L^{\alpha / \beta} \rightarrow \infty \\
\sigma(t) \sim t^{\beta} \text { for } t / L^{\alpha / \beta} \rightarrow 0
\end{gathered}
$$

The parameter $\alpha$ is the static scaling or roughness exponent and $\beta$ is growth exponent. The roughness is also characterized by height-height correlation function,

$$
g(R)=\left\langle\left[Z(x, y)-Z\left(x^{\prime}-y^{\prime}\right)\right]^{2}\right\rangle
$$

where,

$$
R=\left[\left(x, x^{\prime}\right)^{2}+\left(y-y^{\prime}\right)^{2}\right]^{1 / 2}
$$

which scales as, 


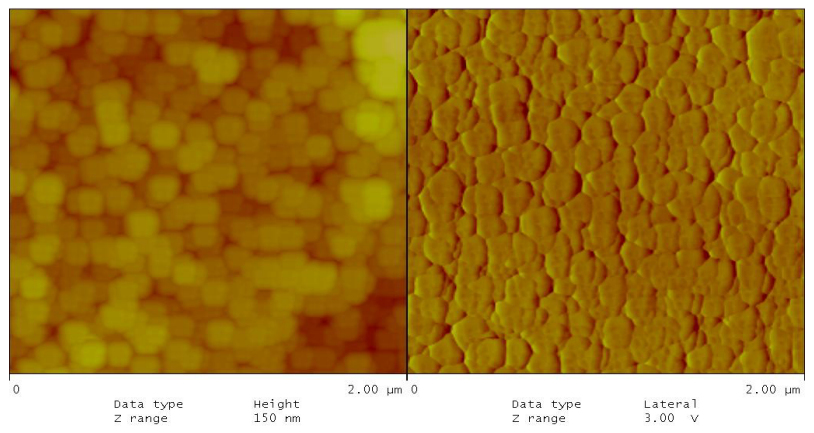

(a)

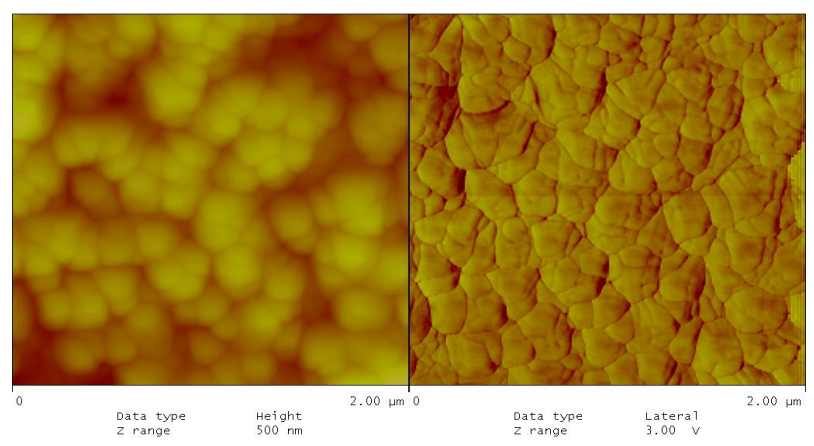

(b)

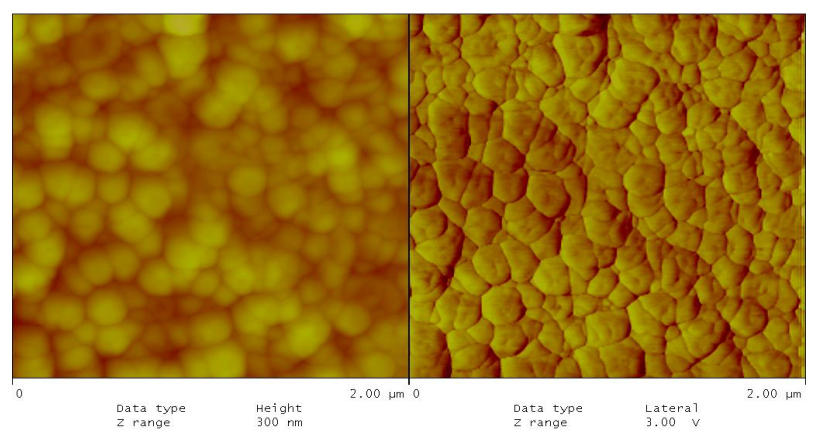

(c)

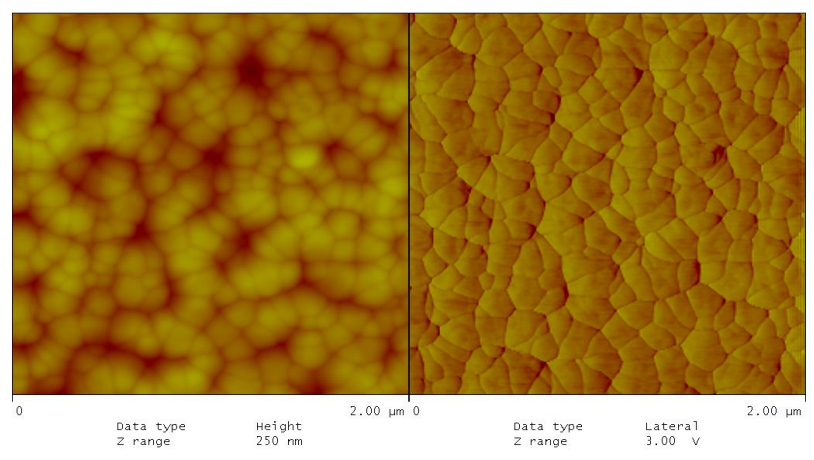

(d)

Figure 2. AFM and LFM images of the film $(2 \times 2 \mu \mathrm{m}) \mathrm{ob}-$ tained by spraying different amount of solutions. (a) for 25 $\mathrm{mL}$ of solution; (b) for $50 \mathrm{~mL}$ of solution; (c) for $75 \mathrm{~mL}$ of solution; (d) for $100 \mathrm{~mL}$ of solution.

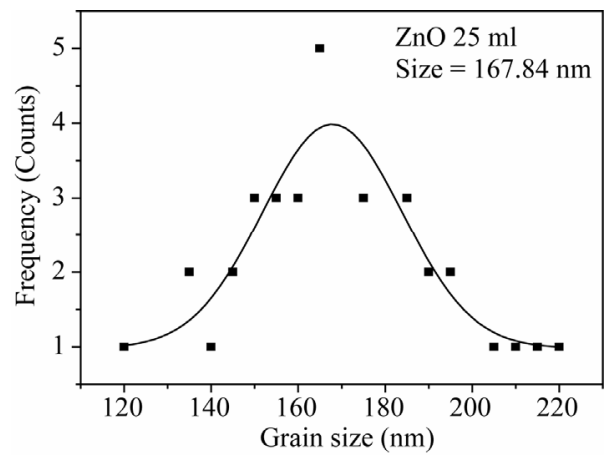

(a)

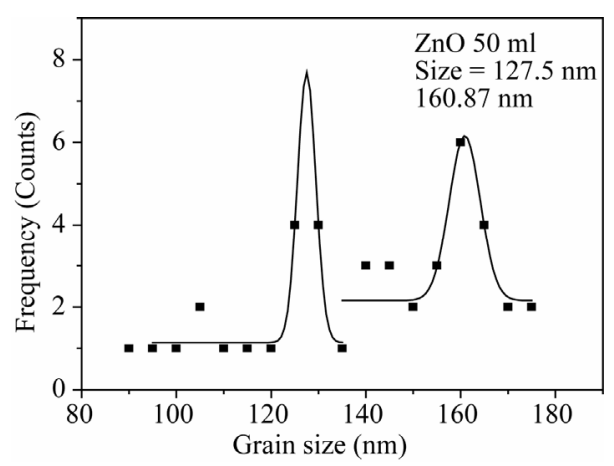

(b)

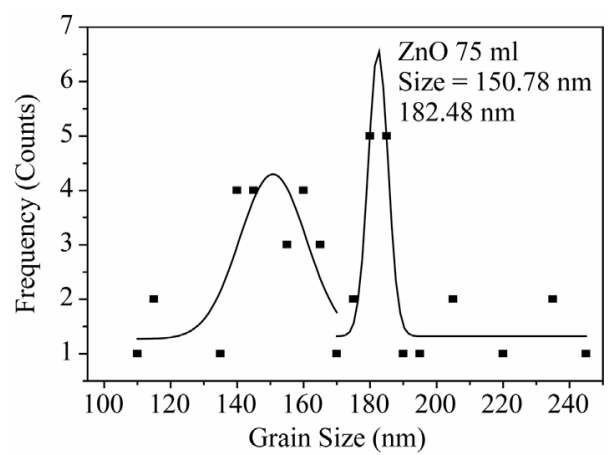

(c)

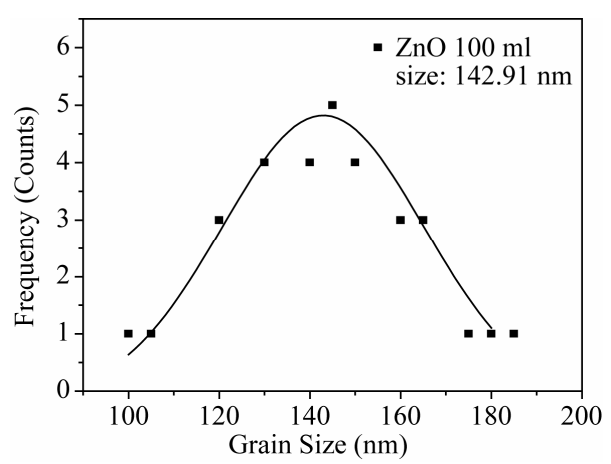

(d)

Figure 3. The $\log g(R)$ vs $\log (R)$ plots for film for different thickness. (a) for $25 \mathrm{~mL}$; (b) for $50 \mathrm{~mL}$; (c) for $75 \mathrm{~mL}$; (d) for $100 \mathrm{~mL}$. 


$$
g(R)=[R]^{2 \alpha} \text { as } R \rightarrow 0
$$

and

$$
g(R)=2 \sigma \text { as } R \rightarrow \infty
$$

In order to get the information regarding the roughness of prepared films with thickness, the quantities $g(R)$ from the AFM data is derived. The plot of $\log g(R)$ vs $\log (R)$ should give the information regarding the roughness exponent $\alpha$ and also the growth exponent $\beta$, (Equation (5)). The value of $g(R)$ has been obtained by scanning the film for smaller areas. The value of $g(R)$ so obtained is plotted in Figure 4(a-d), by plotting $\log g(R)$ vs $\log (R)$ for different amount of precursor solution.

The slope of the upper curve will give the value of $\alpha$ and for the films corresponding to the different thickness is displayed in Figure 5(a). In order to obtain the growth exponent, one needs to carry out in-situ experiments while the film grows. We have attempted to correlate the time factor to the film thickness, as they are proportional to each other at least upto a first approximation. Figure 5(b) shows the log-log of rms roughness verses film thickness, where all the data were taking recorded for $0.274 \times 0.274 \mu \mathrm{m}^{2}$ pixel area. The slope of Figure 5(b) should yield $\beta$. The value of $\beta$ was found to be $0.26 \pm$ 0.089 from the plot of $\log (R)=A t^{\beta}$.

A comparison of our results with the available literature [20], suggest the exponent should falls in the range of $0.2 \leq \alpha \leq 1.0$ and $0.2 \leq \beta \leq 0.56$ for $\mathrm{ZnO}$ films. The results so obtained are in good agreement with the available literature. Thus, $\mathrm{ZnO}$ thin films developed under non-equilibrium conditions behave as self-affine surfaces. The obtained results suggest that the roughness of the film increases with the increases in thickness of the film, i.e. with the increase in the amount of sprayed solution.

Electrical measurements on $\mathrm{ZnO}$ films having different thicknesses were made by using conventional dc-two probe method in the temperature range of $250 \mathrm{~K}$ to $400 \mathrm{~K}$. Contacts made were of copper wires using silver paste on the surface of films. All the films show semiconducting behavior. The activation energy were calculated by using equation as $\rho=\rho_{o}\left(-\mathrm{E}_{\mathrm{a}} / \mathrm{kT}\right)$, where $\rho$ is the resistivity at the temperature $T, \rho_{o}$ is a constant, $k$ is the Boltzmann constant and $E_{a}$ is the activation energy required for transition. The activation energy was found to decrease with increase in thickness of the films. The values so obtained are given in Table 1.

The variation of particle size distributions and associated grain boundaries may be responsible for decrease in activation energy.

\section{Conclusions}

The $\mathrm{ZnO}$ thin films having different thickness prepared

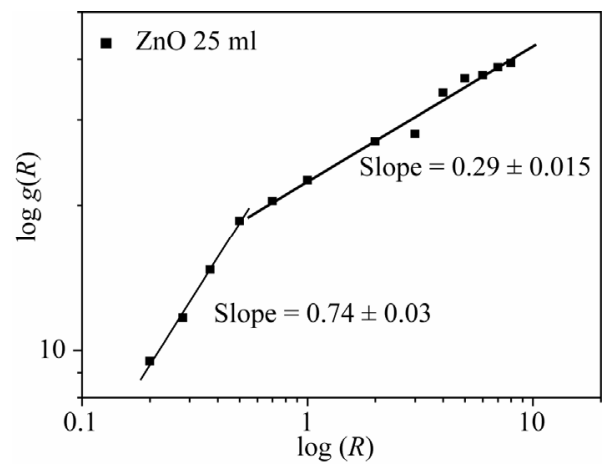

(a)

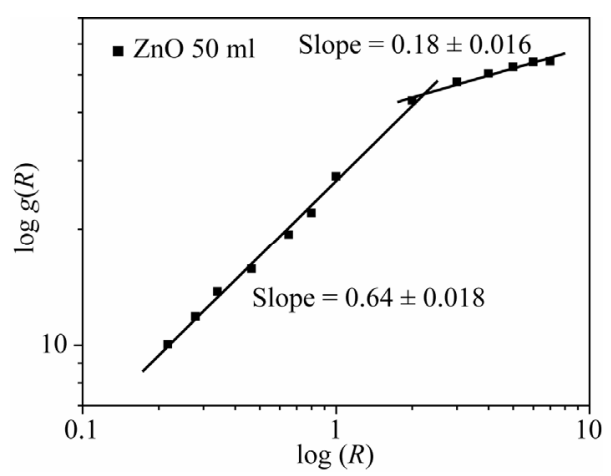

(b)

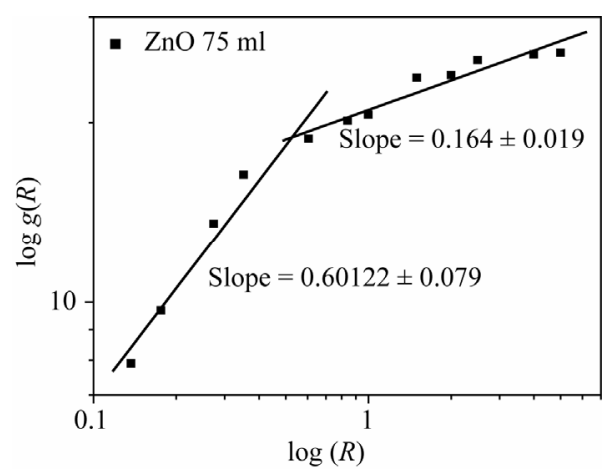

(c)

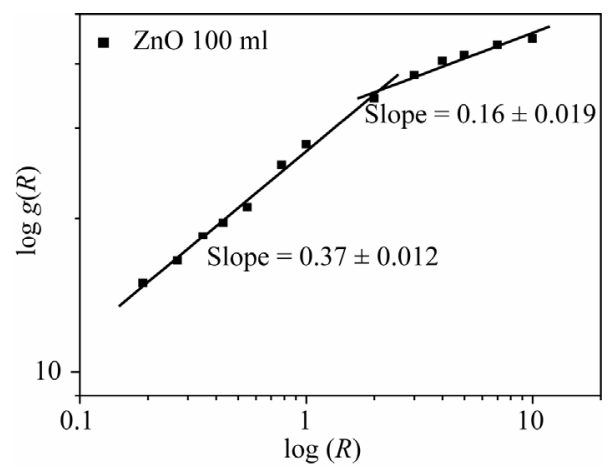

(d)

Figure 4. The $\log g(R)$ vs $\log (R)$ for different amount of precursor solutions. 


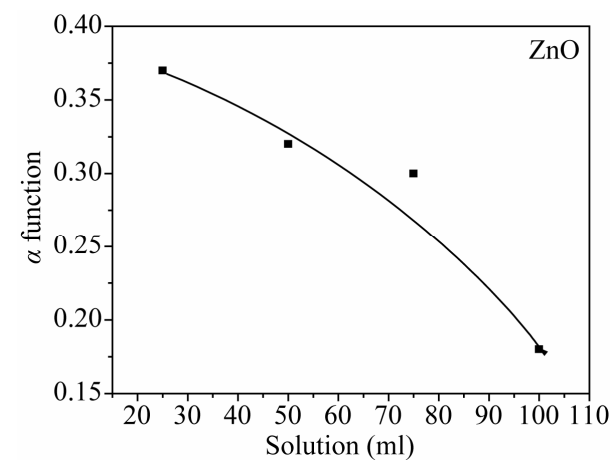

(a)

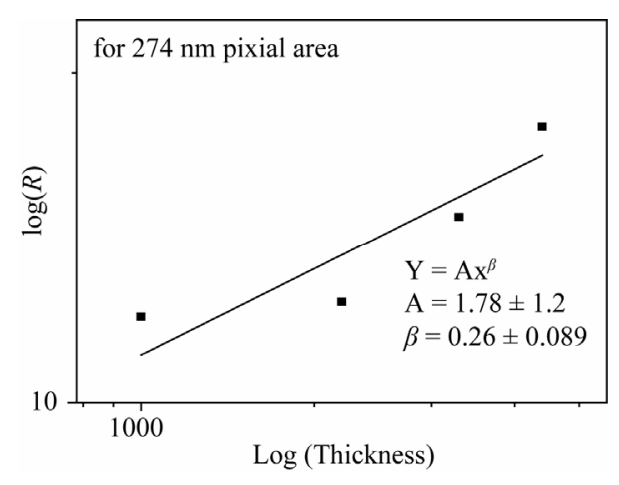

(b)

Figure 5. Variation in $\alpha$ and $\beta$ exponents of films having different thickness.

by Spray pyrolysis technique at constant substrate temperature of $400^{\circ} \mathrm{C}$ on glass substrates, was investigated by XRD, AFM and resistivity measurements. The XRD results suggest that, the film is polycrystalline in nature. The scaling behavior obtained by using height-height correlation method shows that films having different thickness are developed under non-equilibrium condition behaves as self-affine surfaces. The grain size was found to decrease while the roughness of the film increases with increase in thickness of the film. Activation energy was found to decrease with the increase in thickness of the film.

\section{Acknowledgments}

The author from Jabalpur would like to thank the Director and Centre Director of UGC-DAE CSR, Indore for their support under the CRS plan and Mr. L. S. Sharath Chandra and Ms. Swati Pandya for their assistance.

\section{REFERENCES}

[1] T. Lamara, M. Belmahi, O. Elmazria, L. Le Brizoual, J. Bougdira, M. Rémy and P. Alnot, "Freestanding CVD Diamond Elaborated by Pulsed-Microwave-Plasma for ZnO/Diamond SAW Devices," Diamond and Related Materials, Vol. 3, No. 4-8, 2004, pp. 581-584.
[2] T. M. Barnes, J. Leaf, C. Fry and C. A. Wolden, "Room Temperature Chemical Vapor Deposition of C-Axis ZnO," Journal of Crystal Growth, Vol. 274, No. 3-4, 2005, pp. 412-417. doi:10.1016/j.jcrysgro.2004.10.015

[3] A. Bougrinea, A. Hichoub, M. Addou, J. Ebothe', A. Kachouanea and M. Troyonc, "Structural, Optical and Cathodoluminescence Characteristics of Undoped and Tin-Doped ZnO Thin Films Prepared by Spray Pyrolysis," Materials Chemistry and Physics, Vol. 80, No. 2, 2003, pp. 438-445. doi:10.1016/S0254-0584(02)00505-9

[4] S. Liang, H. Sheng, Y. Liu, Z. Huo, Y. Lua and H. Shen, "ZnO Schottky Ultraviolet Photodetectors," Journal of crystal Growth, Vol. 225, No. 2-4, 2001, pp. 110-113. doi:10.1016/S0022-0248(01)00830-2

[5] J. Q. Xu, Y. Q. Pan, Y. A. Shun and Z. Z. Tian, "Grain Size Control and Gas Sensing Properties of $\mathrm{ZnO}$ Gas Sensor," Sensors and Actuators B: Chemical, Vol. 66, No. 1-3, 2000, pp. 277-279. doi:10.1016/S0925-4005(00)00381-6

[6] M. Joseph, H. Tabata, H. Saeki, K. Ueda and T. Kawai, "Fabrication of the Low-Resistive $P$-Type $\mathrm{ZnO}$ by Codoping Method," Physica B: Condensed Matter, Vol. 302-303, 2001, pp. 140-148.

[7] J. M. Bian, X. M. Li, X. D. Gao, W. D. Yu and L. D. Chen, "Deposition and Electrical Properties of N-In Codoped $P$-Type ZnO Films by Ultrasonic Spray Pyrolysis," Applied Physics Letters, Vol. 84, No. 4, 2004, p. 541. doi:10.1063/1.1644331

[8] J. M. Bian, X. M. Li, C.Y. Zhang, W. D. Yu and X. D. Gao, "Synthesis and Characterization of Two-Layer-Structured ZnO P-N Homojunctions by Ultrasonic Spray Pyrolysis," Applied Physics Letters, Vol. 84, No. 19, 2004, pp. 37833785. doi:10.1063/1.1739280

[9] C. Y. Zhang, X. M. Li, J. M. Bian, W. D. Yu and X. D. Gao, "Structural and Electrical Properties of Nitrogen and Aluminum Codoped P-Type ZnO Films," Solid State Communications, Vol. 132, No. 2, 2004, pp. 75-78. doi:10.1016/j.ssc.2004.07.033

[10] J. F. Rommeluere, L. Svob, F. Jomard, J. Mimila-Arroyo, A. Lusson, V. Sallet and Y. Marfaing, "Electrical Activity of Nitrogen Acceptors in ZnO Films Grown by Metalorganic Vapor Phase Epitaxy," Applied Physics Letters, Vol. 83, No. 2, 2003, pp. 287-289. doi:10.1063/1.1592621

[11] C. C. Lin and S. Y. Chen, "Properties of Nitrogen-Implanted $P$-Type $\mathrm{ZnO}$ Films Grown $\mathrm{Si}_{3} \mathrm{~N}_{4} / \mathrm{Si}$ by Radio-Frequency Magnetron Sputtering," Applied Physics Letters, Vol. 84, No. 24, 2004, pp. 5040-5042. doi:10.1063/1.1763640

[12] K. Minegishi, Y. Koiwai, Y. Kikuchi, K. Yano, M. Kasuga and A. Shimizu. "Growth of P-Type Zinc Oxide Films by Chemical Vapor Deposition," Japanese Journal of Applied Physics, Vol. 36(2), No. 11A, 1997, pp. L1453L1455.

[13] T. M. Barnes, K. Olson and C. A. Wolden, "On the Formation and Stability of $P$-Type Conductivity in Nitrogen Doped Zinc Oxide," Applied Physics Letters, Vol. 86, No. 11, 2005, Article ID 112112. 
[14] G. K. Paul and S. K. Sen, "Sol-Gel Preparation, Characterization and Studies on Electrical and Thermoelectrical Properties of Gallium Doped Zinc Oxide Films," Materials Letters, Vol. 57, No. 3, 2002, pp. 742-746. doi:10.1016/S0167-577X(02)00865-0

[15] J. M. Bian, X. M. Li, C. Y. Zhang, W. D. Yu and X. D. Gao, "P-Type $\mathrm{ZnO}$ Films by Monodoping of Nitrogen and ZnO-Based $P-N$ Homojunctions," Applied Physics Letters, Vol. 85, No. 18, 2004, pp. 4070-4072. doi:10.1063/1.1808229

[16] M. Suchea and Kiriakidis, "Surface Characterization of ZnO Transparent Thin Films," Journal of Physics: Conference Series, Vol. 10, No. 10, 2005, pp. 147-150. doi:10.1088/1742-6596/10/1/036

[17] F. Matsukura, H. Ohno, A. Shen and Y. Sugawara,
"Transport Propertiesand Origin of Ferromagnetism in (Ga Mn) As," Physical Review B, Vol. 57, No. 4, 1998, p. R2037. doi:10.1103/PhysRevB.57.R2037

[18] F. Family, "Dynamic Scaling and Phase-Transitions in Interface Growth," Physica A: Statistical Mechanics and Its Applications, Vol. 168, No. 1, 1990, pp. 561.

[19] M. Kardar, G. parisi and Y. C. Zhang, "Dynamic Scaling of Growing Interfaces," Physical Review Letter, Vol. 56, No. 9, 1986, pp. 889-892.

[20] T.-B. Hur, Y.-H. Hwang, H.-K. Kim and H.-L. Park, "Study of the Structural Evolution in $\mathrm{ZnO}$ Thin Film by in Situ Synchrotron X-Ray Scattering," Journal of Applied Physics, Vol. 96, No. 3, 2004, p. 1740. doi:10.1063/1.1762706 